\title{
Lesi Pellegrini-Stieda pada Perempuan: Penemuan Kecil Radiologi tetapi Penting
}

\author{
Monica Cherlady Anastasia ${ }^{1}$, Gregorius Enrico² \\ ${ }^{1}$ Departemen Radiologi, Fakultas Kedokteran dan Ilmu Kesehatan,Universitas Kristen Krida \\ Wacana, Jakarta, Indonesia \\ ${ }^{2}$ Fakultas Kedokteran, Universitas Cenderawasih/RSUD Abepura Jayapura, Indonesia \\ Alamat Korespondensi: monica.cherlady@ukrida.ac.id
}

\begin{abstract}
Abstrak
Lesi Pellegrini-Stieda adalah lesi kecil pasca trauma yang mengalami kalsifikasi (terutama karena cedera olahraga) yang berdekatan dengan margin kondilus femoralis medial, dekat ligamentum kolateral medial (MCL). Karena pasien mengalami gejala, kombinasi anomali radiografi di lokasi yang ditentukan dan cedera MCL sebelumnya dikenal sebagai Sindrom Pellegrini-Stieda. Seorang perempuan lima puluh delapan tahun mengeluh sakit dan bengkak pada lutut bagian tengah kiri dalam lima minggu terakhir. Radiografi lutut kiri menunjukkan kalsifikasi padat lengkung medial ke femur distal di daerah perlekatan MCL proksimal. Terdapat defek kortikal fokal kecil pada kondilus femoralis medial yang berdekatan, efusi sendi kecil terkait pada reses suprapatella, dan enthesofit kecil pada patela superoanterior. Sisa lutut kontralateral pada dasarnya normal. Dengan mengingat sejarah, temuan ini sesuai dengan lesi Pellegrini-Stieda. Lesi Pellegrini-Stieda dianggap sebagai akibat dari pengupasan periosteum femoralis di dekat asal MCL, yang menyebabkan osifikasi heterotopik dan kalsifikasi distrofik. Dalam kasus ini, kalsifikasi lebih berbentuk lengkung, sejajar dengan korteks femoralis, dan radioopak. Penampilan ini cocok dengan lesi Pellegrini-Stieda yang sangat umum. Lesi Pellegrini-Stieda adalah temuan radiologi yang kecil tetapi penting yang tidak boleh dilewatkan sebagai artritis degeneratif pada pasien lanjut usia. Gejala ringan-sedang ditangani secara konservatif, sedangkan untuk kasus yang parah perlu perbaikan melalui pembedahan.
\end{abstract}

Kata kunci: kalsifikasi tendinitis, lesi Pellegrini-Stieda, ligamen kolateral medial femoris, nyeri lutut medial

\section{Pellegrini-Stieda Lesion In Elderly Female: Small but Important Radiology Finding}

\begin{abstract}
Pellegrini-Stieda lesion is a small calcified post-traumatic lesion, mainly because of sport injury, adjacent to the margin of medial femoral condyle, near the medial collateral ligament (MCL). By the symptoms, together with a combination of radiographic anomaly at the designated location and previous MCL injury, findings are known as Pellegrini-Stieda syndrome. A fifty eight year-old female had been complaining pain and swelling on the left medial knee for the last five weeks. Radiographs of the left knee demonstrated curvilinear dense calcification medial to distal femur in the region of proximal MCL attachment. There were a small focal cortical defect in adjacent medial femoral condyle, an associated small joint effusion in suprapatella recess, and small enthesophyte at superoanterior patella. The remainder of contralateral knee was essentially normal. With the history in mind, findings were in keeping with Pellegrini-Stieda lesion. Pellegrini-Stieda lesion is thought to be the result of stripping of the femoral periosteum near the origin of MCL, which leads to heterotopic ossification and dystrophic calcification. In this case, the calcification is more curvilinear in shape, paralleling the femoral cortex, and radioopaque. The appearance in the above case matched that of the very common Pellegrini-Stieda lesion. Pellegrini-Stieda lesion is a small but important radiology finding which should not be missed as a degenerative arthritis in the erderly patient. Mild-moderate symptoms are often treated conservatively, while surgical repair is another option for severe case.
\end{abstract}

Keywords: calcific tendinitis, medial femoral collateral ligament, medial knee pain, Pellegrini-Stieda lesion 


\section{Pendahuluan}

Lesi Pellegrini-Stieda adalah osifikasi pada ligamentum collateral medial di dekat tepi condylus medial femur. Osifikasi terbentuk akibat kejadian trauma sebelumnya (=fraktur Stieda). Fraktur Stieda adalah cedera avulsi dari condylus medial femur pada origo ligamentum collateral medial. Pada tahun 1905, Pellegrini adalah orang yang pertama menjelaskan tanda Pellegrini-Stieda, dan selanjutnya Stieda melaporkan 5 pasien dengan kasus tersebut pada tahun 1908. Augusto Pellegrini (1877-1958) dan Alfred Stieda (18691945) adalah para ahli bedah yang berasal dari Italia dan Jerman. ${ }^{1-6}$

\section{Laporan Kasus}

Seorang perempuan berusia 58 tahun mengeluh nyeri dan bengkak pada sisi medial lutut kiri sejak 5 minggu terakhir. Selama 6 bulan dalam masa pandemi COVID ini, dia berolah raga treadmill intensitas sedang rutin setiap hari. Tidak ditemukan riwayat trauma berat dan penyakit lainnya yang bermakna. Foto $x$-ray genu sinistra memperlihatkan kalsifikasi dens bentuk curvilinier di aspek medial dari femur distal pada regio perlekatan bagian proksimal ligamentum collateral medial. Terdapat defek kortikal kecil di dekat condylus medial femur tersebut. Tampak pula efusi sendi minimal pada recessus suprapatella dan entesofit kecil pada superoanterior patella. Sedangkan genu kontraletral normal. Dengan semua riwayat dan perjalanan klinis pasien, temuan tersebut mencurigakan gambaran lesi Pellegrini-Stieda.

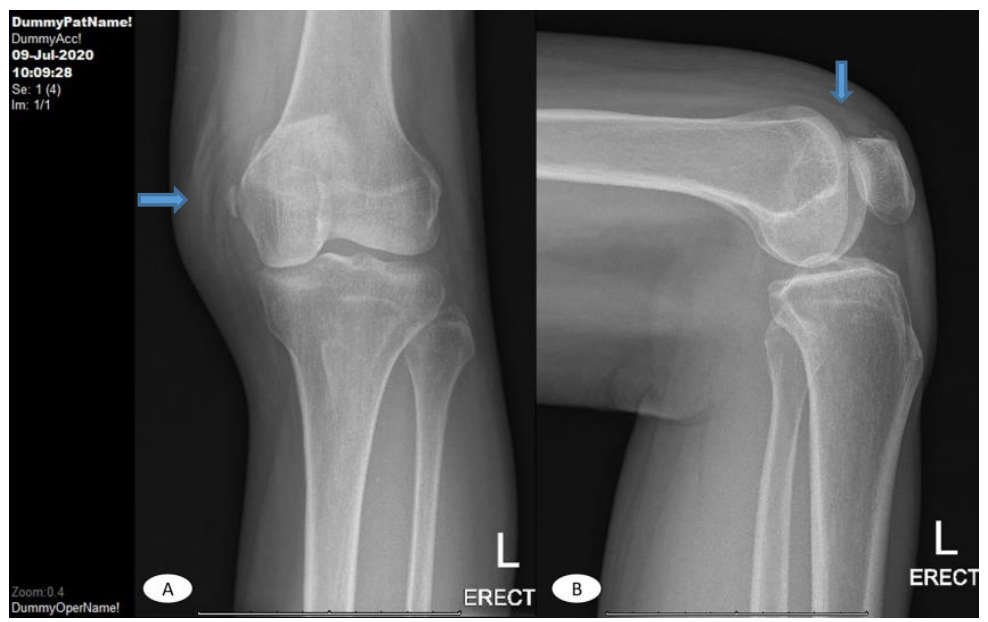

Gambar 1. (A): x-ray Genu Sinistra Proyeksi AP Menunjukkan Opasitas Bentuk Curvilinier Diaspek Medial dari Femur Distal dan Defek Kortikal Kecil Di Dekat Condylus Medial Femur Tersebut $(\Rightarrow)$. (B): Pada Proyeksi Lateral, Terlihat Efusi Sendi Minimal Pada Recessus Suprapatella Dan Entesofit Kecil Pada Superoanterior Patella ( () 


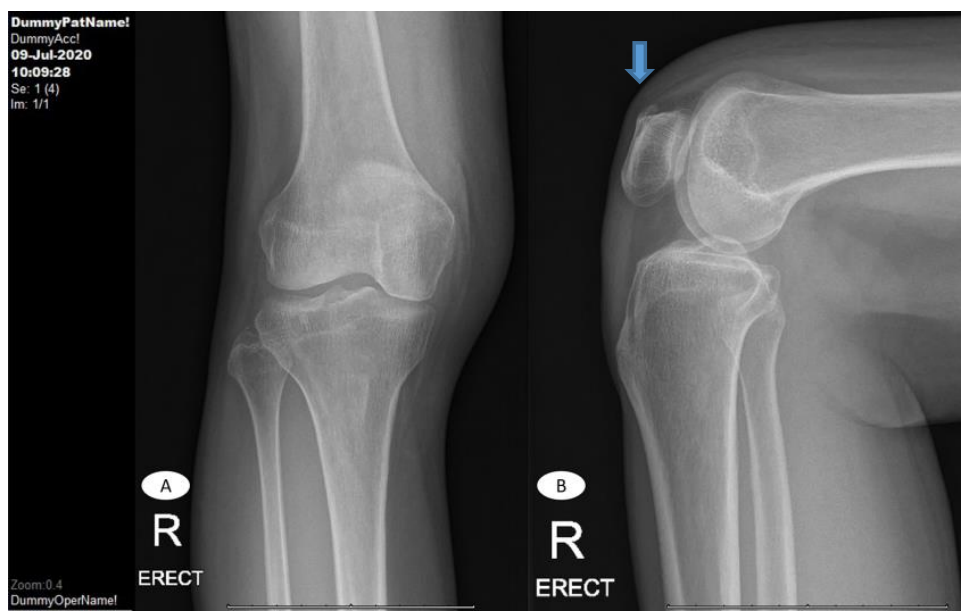

Gambar 2. (A): X-Ray Genu Dekstra Proyeksi AP dan (B): Proyeksi Lateral, Hanya Menunjukkan Entesofit Kecil pada Superoanterior Patella ( $\Downarrow)$. Tidak Ada Patologi Lain yang Bermakna.

\section{Pembahasan}

Ligamentum collateral medial memiliki komponen superficial dan profunda dan penting untuk menjaga stabilitas lutut terutama pada tekanan valgus. ${ }^{7}$ Fraktur Stieda adalah cedera avulsi dari condylus medial femur pada origo ligamentum collateral medial. ${ }^{8-12}$

Memasuki fase penyembuhan, jaringan fibrosa pada ligamentum akan mengalami kalsifikasi dan akhirnya terosifikasi beberapa minggu setelah cedera awal. ${ }^{13}$ Lesi PellegriniStieda sebenarnya adalah osifikasi kronik dari bagian proksimal ligamentum collateral medial akibat fraktur Stieda non-union sebelumnya., ${ }^{7,14}$ Kebanyakan pasien asimtomatik, beberapa bermanifestasi sebagai sindrom Pellegrini-Stieda (manifesitasi klinik nyeri genu sisi medial dan lesi Pellegrini-Stieda). ${ }^{15-18}$

Pada $x$-ray genu, akan tampak sebagai kalsifikasi radioopak linier vertikal atau curvilinier pada bagian proksimal ligamentum collateral medial sejajar dengan korteks condylus medial femur dan dapat menempel atau tidak menempel pada femur. ${ }^{9}$ Lesi ini paling baik dilihat pada proyeksi anterior-posterior (AP). ${ }^{13,14}$ Patologi lain seperti calcific tendinitis pada ligamentum collateral medial dapat memberikan gambaran serupa pada radiologi konvensional. Lesi tampak sebagai kalsifikasi batas tegas dengan tepi yang lebih smooth dan relatif kurang opak dibandingkan lesi Pellegrini-Stieda. ${ }^{19,20}$ Dengan semua riwayat perjalanan klinis dan gambaran radiologi, temuan pada kasus ini sesuai dengan lesi Pellegrini-Stieda.

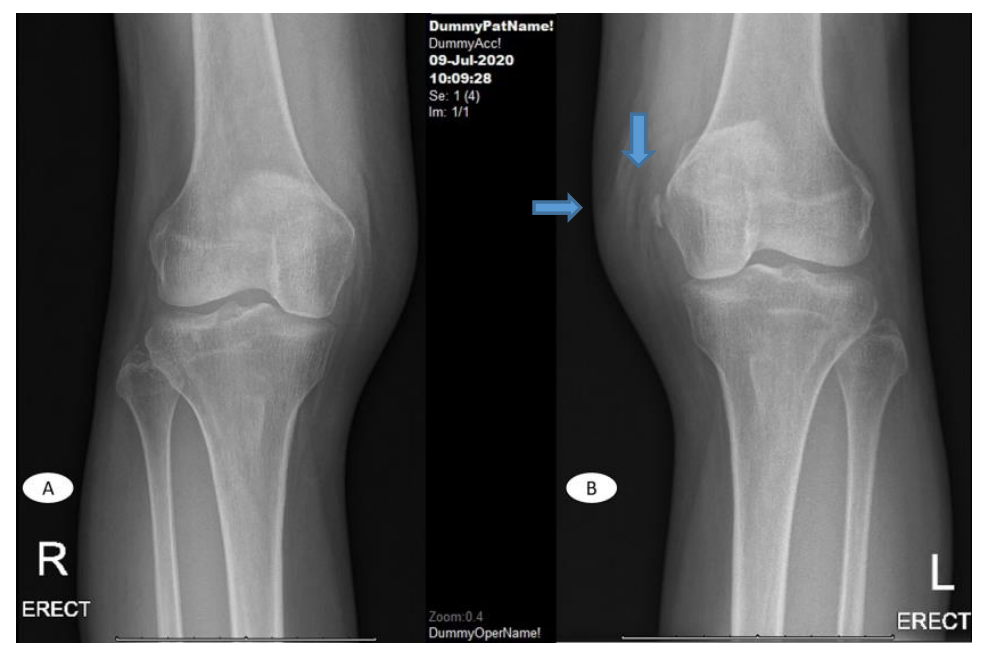

Gambar 3. (A): x-ray Genu Dekstra dan (B): Genu Sinistra proyeksi AP menunjukkan edema jaringan lunak $\Leftrightarrow$ yang cukup prominen pada sisi medial genu sinistra jika dibandingkan genu kontralateral sisi yang sama. Kalsifikasi radioopak linier vertikal atau curvilinier yang tipikal untuk lesi Pellegrini-Stieda ( $($ ). Calcific tendinitis dapat memberikan gambaran radiologi yang menyerupai. 
Kasus ringan-sedang seringnya ditatalaksana secara konservatif dengan injeksi steroid dan fisioterapi. Jika terapi konservatif gagal atau pada kasus refrakter, pembedahan dengan mengeksisi fragmen tulang (segmen kalsifikasi) dan ligament repair memberikan hasil yang baik. ${ }^{14,18}$

\section{Simpulan}

Walaupun berukuran kecil, lesi PellegriniStieda adalah temuan radiologi yang penting terutama pada pasien simtomatik. Tatalaksananya bervariasi dari konservatif hingga pembedahan.

\section{Daftar Pustaka}

1. Hunter TB, Peltier LF, Lund PJ. Radiologic history exhibit: musculoskeletal eponyms: who are those guys? Radiographics. 2000;20(3):819-36.

2. Elhend SB, Doulhousne H, Rokhssi R, Hamoune N. Pellegrini-Stieda syndrome. Pan African Med Journals. 2020;2:1-8. [cited 2021 May 14]. Available from: https://www.clinical-medicine.panafricanmed-journal.com/content/article/2/68/full/

3. Pablo J, Molina, Del Pilar M. Pellegrini Stieda syndrome: more than a radiological sign. Rev. Colomb. Reumatol. 2016;3(3):210212. [cited 2021 May 14]. Available from: http://www.scielo.org.co/scielo.php?pid=S01 21-

$81232016000300010 \&$ script=sci_abstract $\&$ tl ng=en

4. Wiegerinck J I, Somford MP. Review of Stieda's article (1908) on the Pellegrini-Stieda lesion. Journal of ISAKOS: Joint Disorders \& Orthopaedic Sports Medicine. 2016; 1(4), 214-218. doi:10.1136/jisakos-2016-000054.

[cited 2021 May 14]. Available from: https://jisakos.bmj.com/content/1/4/214

5. Ridley LJ, Han J, Ridley WE, Xiang H. Beaktype Pellegrini Stieda lesion. R Aust New Zeal Coll Radiol. 2018:2018. doi:10.1111/17549485.02. [cited 2021 May 14]. Available from: https://onlinelibrary.wiley.com/doi/full/10.11 11/1754-9485.02_12786

6. Mendes LFA, Pretterklieber ML, Cho JH, Garcia GM, Chung CB. Pellegrini - Stieda disease: a heterogeneous disorder not synonymous with ossification / calcification of the tibial collateral ligament - anatomic and imaging investigation. Skelet Radiol.
2006:916-922. doi:10.1007/s00256-006-01745. [cited 2021 May 14]. Available from: https://pubmed.ncbi.nlm.nih.gov/16988801/

7. Adam A, Dixon A.K, Gillard J.H. Grainger \& Allison's Diagnostic radiology. 6th ed. Vol. 1. Philadelphia: Churchill Livingston; 2015. 1082-3 p.

8. Majjhoo A, Sagar H. Pellegrini-Stieda disease calcification of the medial collateral ligament. 2011;17(8):31820568.

doi:10.1097/RHU.0b013e31820568db. [cited 2021 May 16]. Available from: https://pubmed.ncbi.nlm.nih.gov/22126807/

9. Yavuz F, Yasar E, Hazneci B, Ilknur T, Alaca R. Pellegrini-Stieda disease in a patient with cauda equina syndrome. AJPMR. 2011:2011. doi:10.1097/PHM.0b013e3181cf1b95. [cited 2021 May 16 ]. Available from: https://pubmed.ncbi.nlm.nih.gov/20134309/

10. Chen L, Kim PD, Ahmad CS, Levine WN. Medial collateral ligament injuries of the knee : current treatment concepts. 2008:108-13. doi:10.1007/s12178-007-9016-x. [cited 2021 May 16 ]. Available from: https://www.ncbi.nlm.nih.gov/pmc/articles/P MC2684213/

11. Phisitkul P, James SL, Wolf BR, Amendola A. MCL injuries of the knee: current concepts review. Iowa Orthop J. 26(Mcl):77-90. [cited 2021 May 18]. Available from: https://www.ncbi.nlm.nih.gov/pmc/articles/P MC1888587/

12. Mcarthur TA, Pitt MJ, Jr WPG, Nar-ducci Jr CA. Pellegrini-Stieda ossification can also involve the posterior attachment of the MPFL. J Clin Imaging. 2016. doi:10.1016/j.clinimag.2016.06.001

13. Greenspan, Adam LSS. Orthopedic imaging: a practical approach. 5th ed. Philadelphia: Lippincolt Williams \& Wilkins; 2011. 88, 270, $299 \mathrm{p}$.

14. Donna G. Blankenbaker KWD. Diagnostic imaging musculoskeletal trauma. 2nd ed. Philadelphia: Elsevier; 2016. 726-8, 731 p.

15. Wang JC, Shapiro MS. Pellegrini-Stieda syndrome. Am J Orthop (Belle Mead NJ). 1995;24(6):493-7. [cited 2021 May 14]. Available from: https://pubmed.ncbi.nlm.nih.gov/7670873/

16. Somford MP, Lorusso L, Porro A, Loon C Van, Eygendaal D. The Pellegrini - Stieda lesion dissected historically. J. Knee Surg 2018 Jul;31(6):562-7. doi:

$10.1055 / \mathrm{s}-0037$ - 
1604401. [cited 2021 May 18]. Available from:

https://pubmed.ncbi.nlm.nih.gov/28756615/

17. Somford MP, Janssen RPA, Jr CB, Eygendaal D, Meijer D, Roeling TAP. The Pellegrini Stieda lesion of the knee : an anatomical and radiological review. J Knee Surg. 2019;32(7):637-41. doi: 10.1055/s-00381666867. [cited 2021 May 20]. Available from:

https://pubmed.ncbi.nlm.nih.gov/29991078/

18. Theivendran K, Lever CJ, Hart WJ. Good result after surgical treatment of Pellegrini Stieda syndrome. Knee Surg Sport Traumatol Arthrosc.

2009;17:1231-3.

doi:10.1007/s00167-009-0725-0. [cited 2021
May 14 ]. Available from: https://pubmed.ncbi.nlm.nih.gov/19221717/

19. Miller TT. Imaging of the medial and lateral ligaments of the knee. Semin Musculoskelet Radiol. 2009;13(4):340-52. doi: 10.1055/s0029-1242188. [cited 2021 May 21]. Available from: https://pubmed.ncbi.nlm.nih.gov/19890802/

20. Mcanally JL, Southam SL, Mlady GW. New thoughts on the origin of Pellegrini-Stieda : the association of PCL injury and medial femoral epicondylar periosteal stripping. 2009:193-8. doi:10.1007/s00256-008-0604-7. [cited 2021 May 21]. Available from: https://pubmed.ncbi.nlm.nih.gov/18985339/ 